\title{
Optical See-through Head-mounted Display (OST-HMD)-assisted Needle Biopsy for Breast Tumor: A Technical Innovation
}

\author{
SHINICHIRO KASHIWAGI ${ }^{1}$, YUKA ASANO ${ }^{1}$, WATARU GOTO ${ }^{1}$, TAMAMI MORISAKI ${ }^{1}$, \\ MASATSUNE SHIBUTANI ${ }^{2}$, HIROAKI TANAKA ${ }^{2}$, KOSEI HIRAKAWA $^{1,2}$ and MASAICHI OHIRA ${ }^{1,2}$ \\ ${ }^{1}$ Department of Breast and Endocrine Surgery, Osaka City University Graduate School of Medicine, Osaka, Japan; \\ ${ }^{2}$ Department of Gastroenterological Surgery, Osaka City University Graduate School of Medicine, Osaka, Japan
}

\begin{abstract}
Background/Aim: Augmented reality (AR) is a new technology that provides new awareness by using a computer to extend the real environment perceived by humans. Optical see-through head-mounted displays (OST$H M D)$ are worn on the head and can faithfully generate an AR image by wearing the device on the head as a spectacletype device. We developed an ultrasound-guided needle biopsy technique using OST-HMD for breast tumors. Patients and Methods: Moverio BT-35E (Seiko Epson Corp, Nagano, Japan) was used as the OST-HMD device. This technique involves performing needle biopsy under direct vision via the gap at the bottom of the display while the ultrasound images are projected on the display of the OST$H M D$ worn on the head. Results: With this technique, needle biopsy can be executed smoothly with no posture restrictions. A flip shade affixed to the OST-HMD has $2 \%$ transmittance, which enables clearer projection of the images. Conclusion: This article outlines the ultrasoundguided needle biopsy using OST-HMD. We established a safe and accurate biopsy technique with technological innovations using $A R$.
\end{abstract}

Histological and cytological examinations using coreneedle biopsy (CNB) and fine-needle aspiration biopsy are widely performed while detecting lesions by ultrasound (1-

This article is freely accessible online.

Correspondence to: Shinichiro Kashiwagi, MD, Ph.D., Department of Breast and Endocrine Surgery, Osaka City University Graduate School of Medicine, 1-4-3 Asahi-machi, Abeno-ku, Osaka 5458585, Japan. Tel: +81 666453838, Fax: +81 666466450, e-mail: kashiwa@med.osaka-cu.ac.jp

Key Words: Augmented reality, optical see-through head-mounted displays, needle biopsy, breast tumor, virtual reality.
3). The molecular biological mechanisms involved in cancer growth and metastasis have been clarified in recent years, and therapies targeting the biological characteristics of individual cancers are now being selected. In breast cancer, molecular targeted therapies such as endocrine therapy and anti-human epidermal growth factor receptor 2 (HER2) therapy are now selected based on the expression statuses of estrogen receptor, progesterone receptor, and HER2 (4-6). Furthermore, precision medicine is expected to enable the practice of individualized treatment by identifying target genes in the cancer tissue before treatment (7). Thus, it has become necessary to collect sufficient tissue to enable a search for prognostic and predictive factors before treatment $(8,9)$. For this reason, pre-treatment histological diagnosis with tissue specimens has become important. Needle biopsy techniques such as CNB and vacuum-assisted biopsy (VAB), which can be used to search for tissue types and biomarkers with a high degree of diagnostic accuracy, are recommended for masses that are suspected to be clinically malignant (10-13). However, an appropriate approach based on acquired skills is needed to improve the diagnostic accuracy of these techniques.

On the other hand, augmented reality (AR) is a new technology that provides new awareness by using a computer to extend the real environment perceived by humans, that is, by superimposing information on objects in the reality space $(15,16)$. AR was introduced in the medical field in recent years, and there are reports of its use for diagnostic imaging and surgical support (17-22). Optical see-through head-mounted displays (OST-HMD) are worn on the head and can faithfully generate an AR image (21$23)$. There are a number of reports on ultrasound-guided intervention using OST-HMD in the cervical region (24), but there are no reports on breast masses. Therefore, here we developed an ultrasound-guided needle biopsy technique using OST-HMD for breast tumors. 


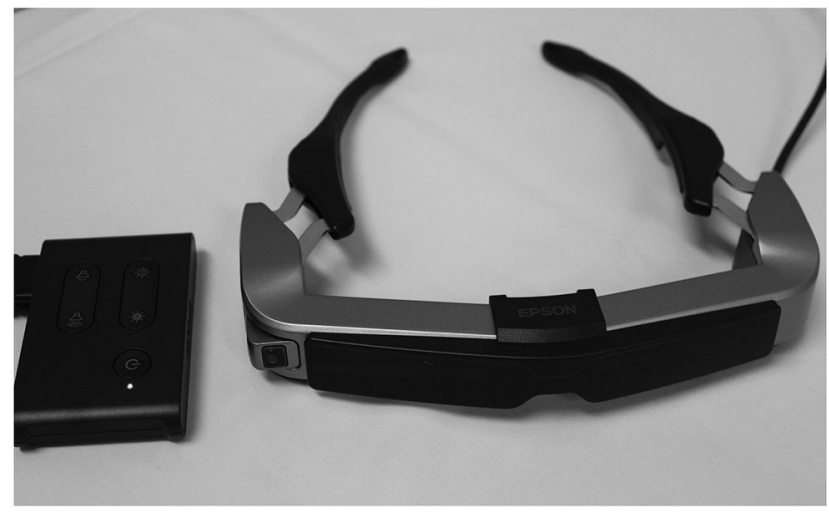

Figure 1. Optical see-through head-mounted displays (OST-HMD) device: Moverio BT-35E (Seiko Epson Corp., Nagano, Japan) was used as the OST-HMD device.

\section{Patients and Methods}

OST-HMD device. Moverio BT-35E (Seiko Epson Corp, Nagano, Japan) was used as the OST-HMD device (Figure 1). Moverio BT-35E/30 was introduced in the consumer market in 2018 as a monitor model that enabled wired connection of a BT-300 (Seiko Epson Corp) to existing systems. This device adopts a binocular liquid-crystal display (LCD) projector-based optical design. These devices are also extremely lightweight, with the BT-35E weighing $119 \mathrm{~g}$ and the BT-30E weighing $69 \mathrm{~g}$, and affordable, making them easy for even non-professionals to use.

Needle biopsy devices. The BARD ${ }^{\mathrm{TM}}$ MAGNUM $^{\mathrm{TM}}$ Reusable Core Biopsy Instrument [Becton Dickinson (BD) (C.R. Bard, Inc.), Tempe, AZ, USA] was used as the CNB device. The EnCor Enspire ${ }^{\mathrm{TM}}$ Breast Biopsy System [BD (C.R. Bard, Inc.)] and EnCor Ultra ${ }^{\mathrm{TM}}$ Breast Biopsy System [BD (C.R. Bard, Inc.)] were used as VAB devices.

Technical procedure. This technique involves performing CNB under direct vision via the gap at the bottom of the display while the ultrasound images are projected on the display of the OST-HMD worn on the head. In conventional ultrasound-guided procedures, needle biopsy is performed while maintaining a posture facing the monitor of a fixed ultrasonic device, which restricts the doctor's posture and movement (Figure 2A and B). However, with this technique, CNB can be executed smoothly with no posture restrictions (Figure 2C and D, Figure 3). A flip shade affixed to the OSTHMD has $2 \%$ transmittance, which enables clearer projection of the images.

In the CNB method, lesions are first confirmed with the ultrasound equipment, and then the operator searches for the best puncture approach (projected onto the OST-HMD).
Using this technique, direct infiltration anesthesia is administered subcutaneously and intradermally with $1 \%$ lidocaine-containing epinephrine under direct vision via the gap at the bottom of the display. Sufficient local infiltration anesthesia is administered along the puncture route and around the lesion under ultrasound guidance projected onto the OST-HMD after reverting to the field of vision. Next, a $1.5-\mathrm{mm}$ skin incision is made under direct vision and the skin is punctured with a $16-\mathrm{G}$ biopsy needle. The target is determined while reconfirming the projected image on the OST-HMD, and the biopsy needle is fired while confirming the safety range. Checks are performed with ultrasound imaging from two directions to ensure that it has penetrated the lesion. The biopsy section is usually divided into two sections, and pathological diagnosis is performed by a pathologist familiar with the pathological diagnosis of breast cancer. The incision is not sutured, and only post-bleeding prevention is performed under pressure.

The biopsy method using VAB is almost the same, but it differs from the CNB technique in that a 10-Gauge biopsy needle is used, local infiltration anesthesia is injected into the retromammary space, and aspiration is performed after penetrating the target.

\section{Results and Discussion}

AR is a variant of virtual reality (VR), adding, deleting, emphasizing, or attenuating information in the surrounding reality at the time in question, literally expanding the real world seen by humans $(15,16)$. While VR replaces reality with an artificially constructed reality, AR modifies part of reality $(15,16)$. VR emphasizes the reality of virtual objects presented to people, while AR also emphasizes the association with context, including real-world position and objects. Therefore, a simple presentation method may be used to extend reality, and head-mounted displays and other such means are used to present the visual information (21, 22). In the medical field, VR is applied as a way to present information for surgical support and diagnostic imaging (17-22, 24).

The main uses of OST-HMD are expected to be those of sub-monitors for inspection/measurement equipment and work performed while checking images sent from drones. It can be used in scenarios in which the operator can check the hand area and any information needed within the field of vision with very little head movement, the work can proceed smoothly and efficiency be improved (23). The BT-35E/30E can output device video information to the monitor without delay by setting up a wired connection to existing systems. Therefore, even in the medical field, in which safety is essential, there are a number of reports on the application of BT-300 and BT-35E to medical technology by connecting to medical devices $(20,21,24)$. 

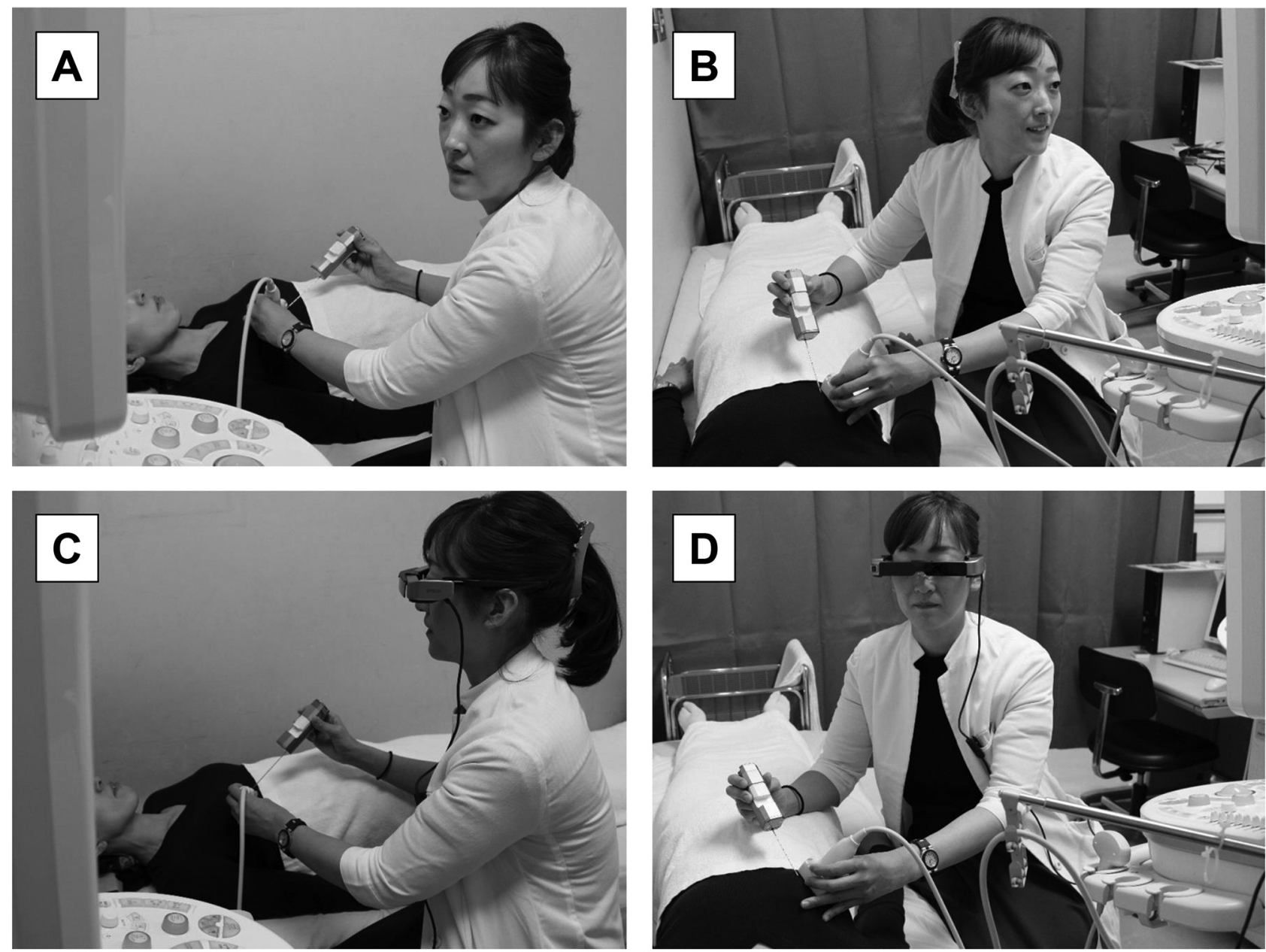

Figure 2. Technical advantage of optical see-through head-mounted displays (OST-HMD) assisted needle biopsy for breast tumor: In conventional ultrasound-guided procedures, needle biopsy is performed while maintaining a posture facing the monitor of a fixed ultrasonic device, which restricts the doctor's posture and movement $(A, B)$. However, with this technique, $C N B$ can be executed smoothly with no posture restrictions $(C, D)$.

Using this procedure, the Moverio BT-35E is used as an OST-HMD device and CNB is implemented under direct vision via the gap at the bottom of the display with ultrasound images on the OST-HMD display worn on the head. Conventional ultrasound-guided CNB is problematic because it restricts the doctor's posture and movements due to the need to perform the procedure while maintaining their posture toward fixed ultrasound equipment. However, with this procedure, even if the head is moved for OST-HMD, the procedure is secured on a safe monitor with the projected image, and CNB can be executed smoothly without posture restrictions. Therefore, the procedure can be performed without the use of restricted postures, even in a limited biopsy space such as an examination room, and even a training surgeon can practice the appropriate procedures without stress.

In this procedure, the BT-35E was used as the OST-HMD, but there are other devices available including [ODG R-7/8/9

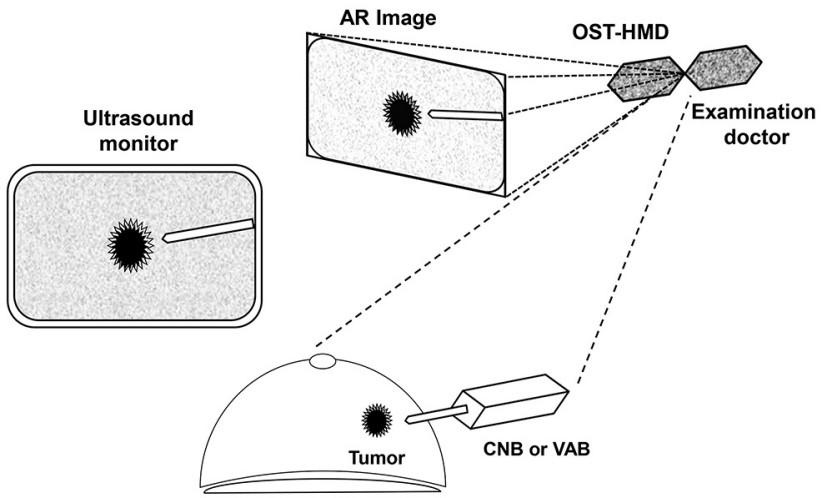

Figure 3. Technique of optical see-through head-mounted displays (OST$H M D$ ) assisted needle biopsy for breast tumor: This technique involves performing needle biopsy under direct vision via the gap at the bottom of the display while the ultrasound images are projected on the display of the OST-HMD worn on the head. 
Glasses System (Osterhout Design Group Inc, San Francisco, CA, USA) and Microsoft HoloLens/2 (Microsoft Corp, Redmond, WA, USA)]. Compared to these devices, BT-35E is inexpensive and compact. The light weight of this device can be a significant advantage when this procedure is performed with the OST-HMD worn on the head. In addition, because of its compact size, it is possible to use the gap at the bottom, enabling monitoring support and use of direct vision techniques at the same time. Although it is possible to see the monitor image without using a flip shade, it is also possible to attach a flip shade to project the ultrasound image more clearly and work under direct vision through the gap at the bottom of the display, thereby adopting a hybrid system using these techniques in tandem.

\section{Conclusion}

This article outlines the ultrasound-guided needle biopsy using OST-HMD. Here, we established a safe and accurate biopsy technique with technological innovations using AR.

\section{Conflicts of Interest}

All of the Authors have no conflicts of interest to disclose regarding this study.

\section{Authors' Contributions}

All Authors were involved in the preparation of this manuscript. SK developed this technique, and wrote the manuscript. SK, YA, WG, and TM performed the biopsy and designed the technique. MS, HT, $\mathrm{KH}$ and MO summarized the data and revised the manuscript. All Authors read and approved the final manuscript.

\section{Acknowledgements}

The Authors thank Natsumi Okahara and Tomomi Okawa (Department of Breast and Endocrine Surgery, Osaka City University Graduate School of Medicine) for the helpful advice regarding data management.

Sources of support: This study was funded by grants from the Japan Society for the Promotion of Science (KAKENHI, Nos. 19K18067, 26461957, and 17K10559) to Shinichiro Kashiwagi.

\section{References}

1 Liberman L: Centennial dissertation. Percutaneous imagingguided core breast biopsy: state of the art at the millennium. AJR Am J Roentgenol 174(5): 1191-1199, 2000. PMID: 10789761. DOI: 10.2214/ajr.174.5.1741191

2 Apesteguía L and Pina LJ: Ultrasound-guided core-needle biopsy of breast lesions. Insights Imaging 2(4): 493-500, 2011. PMID: 22347970. DOI: 10.1007/s13244-011-0090-7

3 Gharib H and Goellner JR: Fine-needle aspiration biopsy of the thyroid: an appraisal. Ann Intern Med 118(4): 282-289, 1993. PMID: 8420446. DOI: 10.7326/0003-4819-118-4-199302150-00007
4 Sorlie T, Tibshirani R, Parker J, Hastie T, Marron JS, Nobel A, Deng S, Johnsen H, Pesich R, Geisler S, Demeter J, Perou CM, Lønning PE, Brown PO, Børresen-Dale AL and Botstein D: Repeated observation of breast tumor subtypes in independent gene expression data sets. Proc Natl Acad Sci U.S.A. 100(14): 8418-8423, 2003. PMID: 12829800. DOI: 10.1073/pnas. 0932692100

5 Abd El-Rehim DM, Ball G, Pinder SE, Rakha E, Paish C, Robertson JF, Macmillan D, Blamey RW and Ellis IO: Highthroughput protein expression analysis using tissue microarray technology of a large well-characterised series identifies biologically distinct classes of breast cancer confirming recent cDNA expression analyses. Int J Cancer 116(3): 340-350, 2005. PMID: 15818618. DOI: 10.1002/ijc.21004

6 Mattie MD, Benz CC, Bowers J, Sensinger K, Wong L, Scott GK, Fedele V, Ginzinger D, Getts R and Haqq C: Optimized high-throughput microRNA expression profiling provides novel biomarker assessment of clinical prostate and breast cancer biopsies. Mol Cancer 5: 24, 2006. PMID: 16784538. DOI: 10.1186/1476-4598-5-24

7 Alexandrov LB, Nik-Zainal S, Wedge DC, Aparicio SA, Behjati S, Biankin AV, Bignell GR, Bolli N, Borg A, Børresen-Dale AL, Boyault S, Burkhardt B, Butler AP, Caldas C, Davies HR, Desmedt C, Eils R, Eyfjörd JE, Foekens JA, Greaves M, Hosoda F, Hutter B, Ilicic T, Imbeaud S, Imielinski M, Jäger N, Jones DT, Jones D, Knappskog S, Kool M, Lakhani SR, López-Otín C, Martin S, Munshi NC, Nakamura H, Northcott PA, Pajic M, Papaemmanuil E, Paradiso A, Pearson JV, Puente XS, Raine K, Ramakrishna M, Richardson AL, Richter J, Rosenstiel P, Schlesner M, Schumacher TN, Span PN, Teague JW, Totoki Y, Tutt AN, Valdés-Mas R, van Buuren MM, van 't Veer L, Vincent-Salomon A, Waddell N, Yates LR, Australian Pancreatic Cancer Genome Initiative, ICGC Breast Cancer Consortium, ICGC MMML-Seq Consortium, ICGC PedBrain, Zucman-Rossi J, Futreal PA, McDermott U, Lichter P, Meyerson M, Grimmond SM, Siebert R, Campo E, Shibata T, Pfister SM, Campbell PJ and Stratton MR: Signatures of mutational processes in human cancer. Nature 500(7463): 415-421, 2013. PMID: 23945592. DOI: $10.1038 /$ nature 12477

8 Rakha EA, El-Rehim DA, Paish C, Green AR, Lee AH, Robertson JF, Blamey RW, Macmillan D and Ellis IO: Basal phenotype identifies a poor prognostic subgroup of breast cancer of clinical importance. Eur J Cancer 42(18): 3149-3156, 2006. PMID: 17055256. DOI: 10.1016/j.ejca.2006.08.015

9 Rakha EA, El-Sayed ME, Green AR, Lee AH, Robertson JF and Ellis IO: Prognostic markers in triple-negative breast cancer. Cancer 109(1): 25-32, 2007. PMID: 17146782. DOI: 10.1002/ cncr.22381

10 Brem RF, Schoonjans JM, Sanow L and Gatewood OM: Reliability of histologic diagnosis of breast cancer with stereotactic vacuum-assisted biopsy. Am Surg 67(4): 388-392, 2001. PMID: 11308011.

11 Verkooijen HM and Core Biopsy After Radiological Localisation (COBRA) Study Group: Diagnostic accuracy of stereotactic large-core needle biopsy for nonpalpable breast disease: results of a multicenter prospective study with $95 \%$ surgical confirmation. Int J Cancer 99(6): 853-859, 2002. PMID: 12115488. DOI: 10.1002/ijc.10419

12 Hoorntje LE, Peeters PH, Mali WP and Borel Rinkes IH: Vacuum-assisted breast biopsy: a critical review. Eur J Cancer 
39(12): 1676-1683, 2003. PMID: 12888361. DOI: 10.1016/ s0959-8049(03)00421-0

13 Kashiwagi S, Onoda N, Asano Y, Noda S, Kawajiri H, Takashima T, Ohsawa M, Kitagawa $S$ and Hirakawa K: Adjunctive imprint cytology of core needle biopsy specimens improved diagnostic accuracy for breast cancer. Springerplus 2: 372, 2013. PMID: 24010031. DOI: 10.1186/2193-1801-2-372

14 Perretta T, Lamacchia F, Ferrari D, Beninati E, DI Tosto F, DE Stasio V, Meucci R, DI Stefano C, Buonomo OC, Vanni G and Pistolese CA: Evaluation of ultrasound-guided 8-gauge vacuumassisted excision system for the removal of US-detectable breast lesions. Anticancer Res 40(3): 1719-1729, 2020. PMID: 32132080. DOI: 10.21873 /anticanres.14125

$15 \mathrm{Kim}$ Y, Kim H and Kim YO: Virtual reality and augmented reality in plastic surgery: a review. Arch Plast Surg 44(3): 179187, 2017. PMID: 28573091. DOI: 10.5999/aps.2017.44.3.179

16 Quintero J, Baldiris S, Rubira R, Cerón J and Velez G: Augmented reality in educational inclusion. A systematic review on the last decade. Front Psychol 10: 1835, 2019. PMID: 31456716. DOI: 10.3389/fpsyg.2019.01835

17 Vávra P, Roman J, Zonča P, Ihnát P, Němec M, Kumar J, Habib $\mathrm{N}$ and El-Gendi A: Recent development of augmented reality in surgery: a review. J Healthc Eng 2017: 4574172, 2017. PMID: 29065604. DOI: 10.1155/2017/4574172

18 Meola A, Cutolo F, Carbone M, Cagnazzo F, Ferrari M and Ferrari V: Augmented reality in neurosurgery: a systematic review. Neurosurg Rev 40(4): 537-548, 2017. PMID: 27154018. DOI: $10.1007 / \mathrm{s} 10143-016-0732-9$

19 Yoo JS, Patel DS, Hrynewycz NM, Brundage TS and Singh K: The utility of virtual reality and augmented reality in spine surgery. Ann Transl Med 7(Suppl 5): S171, 2019. PMID: 31624737. DOI: $10.21037 / \mathrm{atm} .2019 .06 .38$
20 Nishimoto S, Tonooka M, Fujita K, Sotsuka Y, Fujiwara T, Kawai K and Kakibuchi M: An augmented reality system in lymphatico-venous anastomosis surgery. J Surg Case Rep 2016(5): rjw047, 2016. PMID: 27154749. DOI: 10.1093/ jscr/rjw047

21 Kaneko N, Sato M, Takeshima T, Sehara Y and Watanabe E: Ultrasound-guided central venous catheterization using an optical see-through head-mounted display: A pilot study. J Clin Ultrasound 44(8): 487-491, 2016. PMID: 27297681. DOI: $10.1002 / \mathrm{jcu} .22374$

22 Qian L, Barthel A, Johnson A, Osgood G, Kazanzides P, Navab $\mathrm{N}$ and Fuerst B: Comparison of optical see-through headmounted displays for surgical interventions with object-anchored 2D-display. Int J Comput Assist Radiol Surg 12(6): 901-910, 2017. PMID: 28343301. DOI: 10.1007/s11548-017-1564-y

23 Rahman R, Wood ME, Qian L, Price CL, Johnson AA and Osgood GM: Head-mounted display use in surgery: a systematic review. Surg Innov 27(1): 88-100, 2020. PMID: 31514682. DOI: $10.1177 / 1553350619871787$

24 Kaneko N, Tsunoda M, Mitsuhashi M, Okubo K, Takeshima T, Sehara Y, Nagai M and Kawai K: Ultrasound-guided fine-needle aspiration in the neck region using an optical see-through headmounted display: a randomized controlled trial. J Ultrasound Med 36(10): 2071-2077, 2017. PMID: 28504313. DOI: 10.1002/ jum.14237 